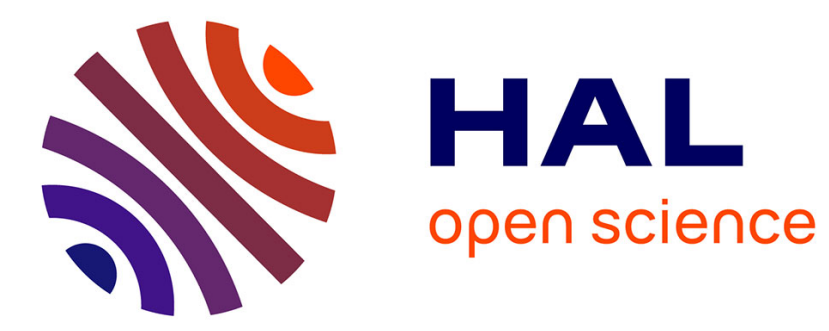

\title{
Molecular tectonics: control of crystalline sequences
}

\author{
Cyril R. R. Adolf, Sylvie Ferlay, Mir Wais Hosseini
}

\section{To cite this version:}

Cyril R. R. Adolf, Sylvie Ferlay, Mir Wais Hosseini. Molecular tectonics: control of crystalline sequences. CrystEngComm, 2018, 20 (16), pp.2233-2236. 10.1039/C8CE00478A . hal-02300918

\section{HAL Id: hal-02300918 \\ https://hal.science/hal-02300918}

Submitted on 24 Nov 2020

HAL is a multi-disciplinary open access archive for the deposit and dissemination of scientific research documents, whether they are published or not. The documents may come from teaching and research institutions in France or abroad, or from public or private research centers.
L'archive ouverte pluridisciplinaire HAL, est destinée au dépôt et à la diffusion de documents scientifiques de niveau recherche, publiés ou non, émanant des établissements d'enseignement et de recherche français ou étrangers, des laboratoires publics ou privés. 


\section{Journal Name}

\section{COMMUNICATION}

\section{Molecular Tectonics: control of crystalline sequences}

Received 00th January 20xx, Accepted 00th January 20xx

DOI: $10.1039 / \times 0 x \times 00000 x$

\author{
Cyril R. R. Adolf, ${ }^{a}$ Sylvie Ferlay ${ }^{a}, *$ and Mir Wais Hosseini ${ }^{a, *}$
}

www.rsc.org/

Following the molecular tectonics approach, the design and preparation of crystalline entities with controled sequences were achieved by crystal welding processes based on isostructural and almost isometric coloured crystals. The strategy was based on stepwise 3D epitaxial growth.

Both for fundamental and applied sciences, the understanding and design of crystalline complex molecular systems with strict control of the short and long range orders both at the microscopic and macroscopic levels is of prime importance for developments of new solid state materials and devices. Hierarchical construction of crystalline species resulting from the interconnection of single crystals into networks of crystals leading to sequences of crystalline zones may be a powerful tool for the generating new crystalline task specific materials. This may be achieved by the molecular tectonics approach ${ }^{1}$ for which molecular crystals are considered as supramolecular entities ${ }^{2,3}$ seen as periodic molecular networks ${ }^{4}$ composed of interconnected complementary tectons ${ }^{5}$ bearing within their framework specific geometric and recognition information. Beyond crystal engineering, ${ }^{6}$ engineering multi-zone single crystals such as core-shell crystals ${ }^{7-9}$ and welded crystals ${ }^{10}$ remain a challenge. For the molecular tectonics approach, four different categories of molecular crystals may be defined (Figure 1): crystal, a molecular architecture possessing periodicity both in position and in composition (Figure 1a); crystalline solid solution, a periodic assembly in position but random in composition (Figure 1b); a core-shell crystal composed of different interconnected crystalline zones each periodic in position and in composition (Figure 1c), this type of organization is obtained by stepwise hierarchical selfassembly processes and finally welded crystal, multi-zone architectures composed of at least

\footnotetext{
a. Molecular Tectonics Laboratory, University of Strasbourg, CNRS, CMC UMR 7140, F-67000 Strasbourg, France

Electronic Supplementary Information (ESI) available: Synthesis of trimetallic 1D networks of crystals and their X-ray characterisation. See DOI: $10.1039 / \mathrm{x} 0 \mathrm{xx} 00000 \mathrm{x}$
}

This journal is (C) The Royal Society of Chemistry 20xx three domains periodic in position and in composition within each crystalline domain (Figure 1d). This type of architecture may be obtained by stepwise selfassembly strategy. It is worth noting that except for a molecular crystal, for a solid solution the tectons need to be similar. For the other two categories, obtained by 3D epitaxial growth processes, the crystalline domains must be isostructural and almost isometric.

\section{Crystal Crystalline Solid Solution}

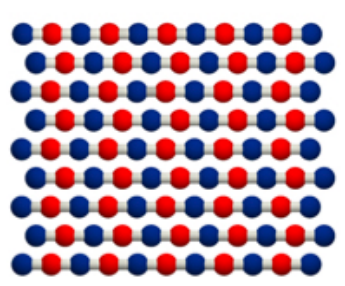

a

Core-Shell Crystal

-000000000 $0-000000$ 00000000 - 00000000 -000000000 -00000000 -000000000 00000000

c

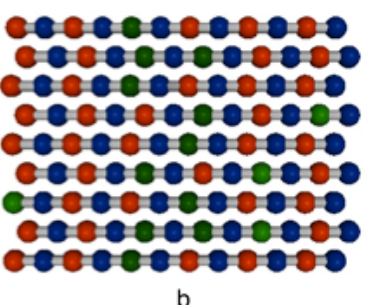

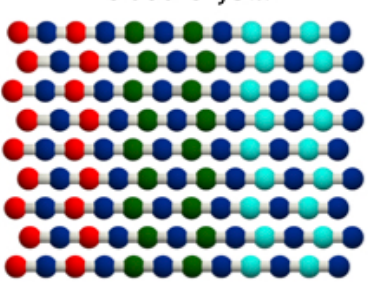

Isostructural Complementary tectons Recognition pattern

Figure 1: Schematic representations (2D projection) of a portion of a) a crystal (periodic in position and in composition), b) a crystalline solid solution (periodic in position and random in composition), c) a core-shell crystal (periodic in position obtained by stepwise epitaxial growth) and d) a crystalline sequence (periodic in position displaying three crystalline zones). Red, blue and green spheres represent complementary tectons and the grey cylinder represents a recognition pattern connecting consecutive tectons.

In this contribution, we report on the extensive use of crystal welding in solution and under mild conditions using 3D 
epitaxial growth for the generation of a variety of crystalline materials displaying controlled and imposed sequences.

Among many possible attractive interactions that can be used for interconnecting consecutive tectons by selfassembly processes into periodic networks, directional $\mathrm{H}$-bonding combined with charge-charge electrostatic interactions (charge-assisted $\mathrm{H}$-bonding) ${ }^{11}$ is particularly interesting. ${ }^{1 \mathrm{c}, 12}$ Using such interactions, a variety of isostructural and almost isometric crystals has been generated by combining dicationic organic tectons and dianionic metallatectons as $\mathrm{H}$-bond donors and acceptors respectively. ${ }^{12}$ Furthermore, they were used to form core-shell crystals by 3D epitaxial growth processes. ${ }^{8}$ The same strategy was recently extended to the use of coordination bond using metallatectons and metal cations. ${ }^{9}$

Combinations of the dicationic $\mathrm{H}$-bond donor organic tecton $1^{2+}$ with tetraanionic complexes $\left[\mathrm{ML}_{2}\right]^{4-}(\mathrm{M}=\mathrm{Mn}, \mathrm{Fe}$, $\mathrm{Co}, \mathrm{Ni}, \mathrm{Cu}$ or $\mathrm{Zn}$ ) as $\mathrm{H}$-bond acceptor (Figure 2), were shown to lead to the formation of robust isostructural (monoclinic, C2/c, $Z=4$ ) and almost isometric crystals $\mathbf{1}_{2}-\mathrm{ML}_{2}$ (see table S1, ESI). ${ }^{10}$ The latter are based on the formation of 3D $\mathrm{H}$-bonded networks between $\mathrm{H}$-bond donor and acceptor tectons.

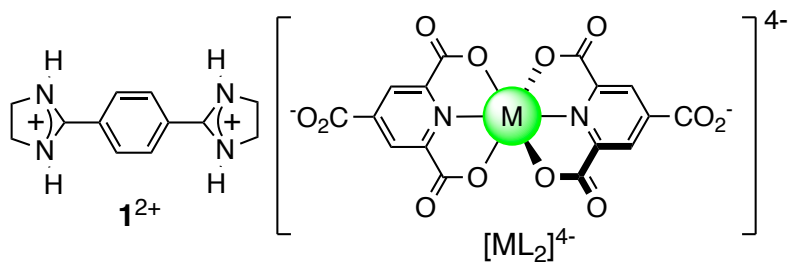

$\mathrm{M}(\mathrm{II})=\mathrm{Mn}, \mathrm{Fe}, \mathrm{Co}, \mathrm{Ni}, \mathrm{Cu}, \mathrm{Zn}$

Figure 2: Dicationic $\mathbf{1}^{2+}$ and tetraanionic $\left[\mathrm{ML}_{2}\right]^{4-}(\mathrm{Mn}, \mathrm{Fe}, \mathrm{Co}, \mathrm{Ni}, \mathrm{Cu}$ or $\mathrm{Zn})$ tectons used for the formation of isostructural and almost isometric crystals.

Interestingly, except for $\mathbf{1}_{2}-\mathrm{ZnL}_{2}$ which is colourless, depending on the nature of the divalent cation ( $\mathrm{M}=\mathrm{Mn}, \mathrm{Fe}, \mathrm{Co}, \mathrm{Ni}, \mathrm{Cu}$ ) coloured rod type crystals are obtained (Figure 3). ${ }^{10}$ For the sake of clarty of description, $\mathbf{1}_{2}-\mathrm{ML}_{2}(\mathrm{M}=\mathrm{Mn}, \mathrm{Fe}, \mathrm{Co}, \mathrm{Ni}, \mathrm{Cu}$ or $\mathrm{Zn}$ ) crystals will be designated as $\mathbf{A}$, $\mathbf{B}$ or $\mathbf{C}$ in the following sections.

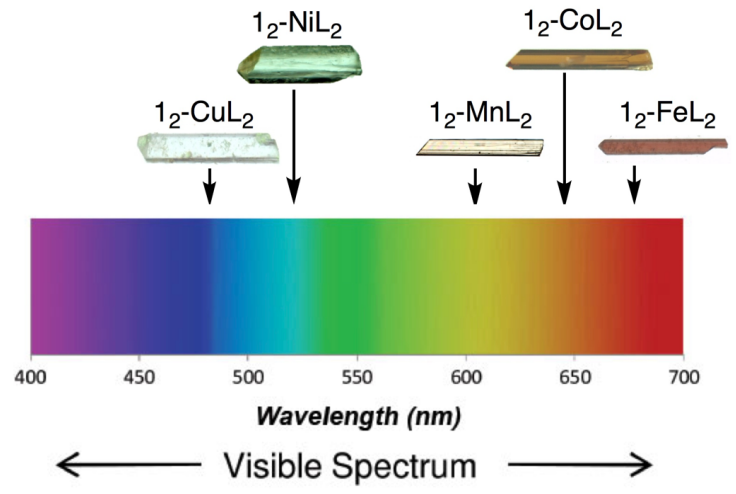

Figure 3: Photographs of isostructural and almost isometric coloured rod-type crystals $\mathbf{1}_{2}-\mathrm{ML}_{2}$ displaying absorption bands in the visible range.
In a preliminary investigation, ${ }^{10}$ using a series of rod-type isostructural and almost isometric coloured crystals (Figure 3), we have demonstrated that by 3D epitaxial growth, it is possible to generate, in solution and under mild conditions, core-shell crystals of the type B@A. Furthermore, two crystals A aligned and oriented along the fastest growth axis $c$ (Figure 4a), may be welded in solution at room temperature into a welded single crystal A-B-A (Figure 4b). However, it must be noticed that since the welding process by 3D epitaxial growth takes place in solution, the growth phenomena operates at the two extremities of the welded crystal as well at the other two directions of space $a$ and $b$ (Figure 4b) leading thus to a welded core-shell crystal. Since the growth process is considerably faster along the $c$ axis, by neglecting the growth along $a$ and $b$ axes, the welded crystal may be seen as a crystal displaying a palindromic $\boldsymbol{B}-\boldsymbol{A}-\boldsymbol{B}-\boldsymbol{A}-\boldsymbol{B}$ sequence composed of five crystalline zones (Figure $4 \mathrm{C}$ ).

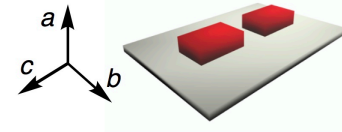

a

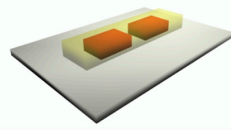

b

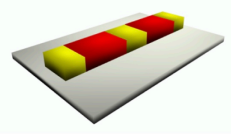

C
Figure 4: Schematic representation of two aligned crystals $\boldsymbol{A}$ along the fastest growth axis $C$ (a), welding of two crystals $\boldsymbol{A}$ by a crystalline phase $\boldsymbol{B}$ (b) and simplified representation of the welded crystal along the $c$ axis leading to the palindromic $\boldsymbol{B}-\boldsymbol{A}-\boldsymbol{B}$ $\boldsymbol{A}-\boldsymbol{B}$ sequence (c). Crystals $\boldsymbol{A}$ and $\boldsymbol{B}$ differ by the nature of $\mathrm{M}$ in the $\mathbf{1}_{2}-\mathrm{ML}_{2}$ unit (see figure 1).

The welding approach described above is rather versatile and may be further applied to the formation of strictly controlled sophisticated sequenced crystals. Indeed, instead of welding two identical crystals by a second crystalline phase (Figure 4), the approach may be extended to the welding of two different crystals $\mathbf{A}$ and $\mathbf{B}$ (Figure $5 \mathrm{a}$ ) by a third crystalline domain $\mathbf{C}$ (Figure $5 \mathrm{~b}$ ) leading to a non-symmetric sequence $\boldsymbol{C}-\boldsymbol{A}-\boldsymbol{C}-\boldsymbol{B}-\boldsymbol{C}$ along the $c$ axis (Figure $5 c$ ).

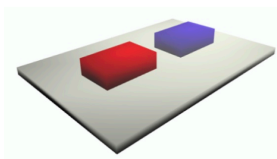

a

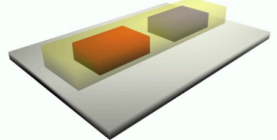

b

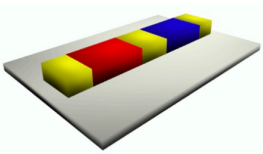

C
Figure 5: Schematic representation of aligned crystals $\boldsymbol{A}$ and $\boldsymbol{B}$ along the fastest growth axis $C(a)$, welding of crystals $\boldsymbol{A}$ and $\boldsymbol{B}$ by a crystalline phase $\boldsymbol{C}(\mathrm{b})$ and simplified representation of the welded crystal along the $c$ axis leading to the unsymmetrical $\boldsymbol{C}$ - $\boldsymbol{A}$ $\boldsymbol{C}-\boldsymbol{B}-\boldsymbol{C}$ sequence (c). Crystals $\boldsymbol{A}$ and $\boldsymbol{B}$ differ by the nature of $\mathrm{M}$ in the $\mathbf{1}_{2}-\mathrm{ML}_{2}$ unit (see figure 1).

It is worth noting that crystals $\mathbf{1}_{2}-\mathrm{ML}_{2}(\mathrm{M}=\mathrm{Mn}, \mathrm{Fe}, \mathrm{Co}, \mathrm{Ni}, \mathrm{Cu}$ or $\mathrm{Zn}$ ) possessing different colours, display a rod-type morphology with their extremities forming an angle with the fastest growth axis $c$ (Figure 3 ). We used these two observations to align the crystals along the $\mathrm{c}$ axis and to orient them. The orientation was further confirmed by face indexation. These two issues are crucial for optimal epitaxial growth. 
In a Petri dish, two different crystals $\mathbf{1}_{2}-\mathrm{FeL}_{2}$ and $\mathbf{1}_{2}-\mathrm{CoL}_{2}$ were aligned and oriented along the $c$ axis (Figure 6a) and covered with a solution containing $\mathrm{NiL}_{2}$ and $\mathbf{1}^{2+}$ cation and the welding process was monitored using a microscope (see experimental section, ESI). The growth process led to the formation of the welded entity as a single crystal displaying the $\mathbf{N i}-\mathbf{F e}-\mathbf{N i}-\mathrm{Co}-\mathbf{N i}$ sequence (Figure $6 \mathrm{~b}$ ). The single crystal nature of the latter was established by X-ray diffraction on the welded crystal. Furthermore, cell parameters of different crystalline zones were determined by focussing the X-ray beam on desired domains (see experimental characterisation section, ESI).

The same procedure was applied to weld $\mathbf{1}_{2}-\mathrm{FeL} 2$ and $\mathbf{1}_{2}-\mathrm{MnL}_{2}$ crystals (Figure $6 \mathrm{c}$ ) by $\mathbf{1}_{2}-\mathrm{NiL}_{2}$. The process afforded the unsymmetrical $\mathbf{N i}-\mathbf{F e}-\mathbf{N i}-\mathbf{M n}-\mathbf{N i}$ sequence composed of 5 crystalline interconnected zones (Figure $6 \mathrm{~d}$ ). The generality of the strategy was further demonstrated by welding $\mathbf{1}_{2}-\mathrm{ZnL}_{2}$ and $\mathbf{1}_{2}-\mathrm{CoL}_{2}$ crystals (Figure 6e) by $\mathbf{1}_{2}-\mathrm{NiL}_{2}$ (Figure $6 \mathrm{f}$ ) displaying the Ni-Zn-Ni-Co-Ni sequence.

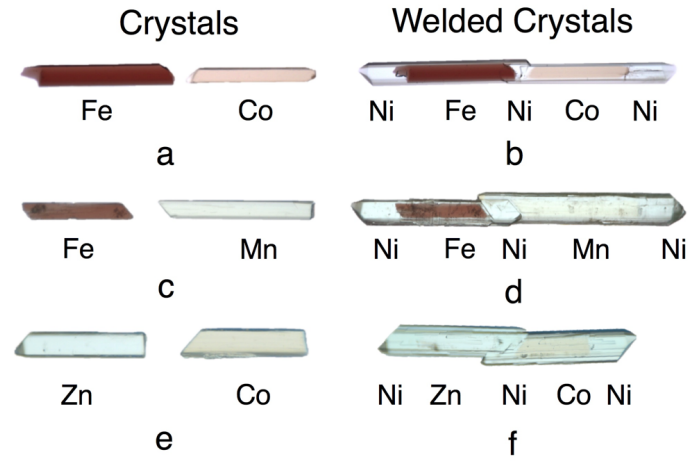

Figure 6: Photographs of two aligned crystals along the $c$ axis containing Fe and $\mathrm{Co}$ (a) and their welding by a crystalline phase containing $\mathrm{Ni}$ leading to the $\mathrm{Ni}-\mathrm{Fe}-\mathrm{Ni}$-Co- $\mathrm{Ni}$ sequence (b) and two crystals containing $\mathrm{Fe}$ and $\mathrm{Mn}$ (c) and their welding by a crystalline phase based on $\mathrm{Ni}$ leading to the $\mathrm{Ni}-\mathrm{Fe}-\mathrm{Ni}-\mathrm{Co}-\mathrm{Ni}$ sequence (d) and two aligned crystals contained $\mathrm{Zn}$ and $\mathrm{Co}(\mathrm{e})$ and their welding by a crystalline phase based on Ni leading to the $\mathbf{N i}-\mathbf{Z n}-\mathbf{N i}-\mathrm{Co}-\mathbf{N i}$ sequence (f).

The stepwise strategy for the preparation of sequenced crystals by 3D epitaxial growth presented here is rather versatile and offers many design possibilities for the formation of crystalline mosaics composed of several zones. In particular, starting with a welded crystal of the $\boldsymbol{A}-\boldsymbol{B}-\boldsymbol{A}$ (Figure 7a), a coreshell crystal may be formed by epitaxial growth using a crystalline shell $\boldsymbol{C}$ (Figure $7 \mathrm{~b}$ ). Again, by neglecting the growth along the $a$ and $b$ axes, the single crystal thus obtained may be described as $\boldsymbol{C}-\boldsymbol{B}-\boldsymbol{A}-\boldsymbol{B}-\boldsymbol{A}-\boldsymbol{B}-\boldsymbol{C}$ sequence along the $\boldsymbol{C}$ axis composed of seven crystalline domains (Figure $7 \mathrm{C}$ ).

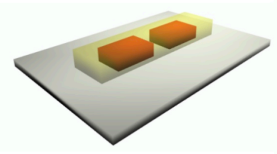

a

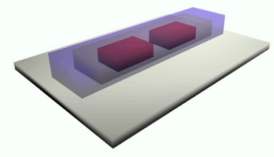

b

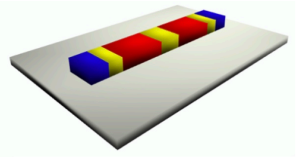

C
Figure 7: Schematic representations of the welded crystal $\boldsymbol{A}-\boldsymbol{B}-\boldsymbol{A}$ (a) and the core-shel crystals $C @(A-B-A)$ (b) leading to the $\boldsymbol{C}-\boldsymbol{B}-\boldsymbol{A}-\boldsymbol{B}-\boldsymbol{A}-\boldsymbol{B}-\boldsymbol{C}$ sequence $(\mathrm{c})$ along the $\mathrm{c}$ axis.

Starting with the Fe-Zn-Fe welded crystal displaying the $\mathbf{Z n - F e - ~}$ $\mathbf{Z n}$-Fe-Zn sequence (Figure $8 \mathrm{a}$ ), the formation of the core-shell crystal Ni@(Fe-Zn-Fe) was achieved using a solution containing $\mathrm{NiL}_{2}$ and $\mathbf{1}^{2+}$ (Figure $8 \mathrm{~b}$ ). The latter is composed of $\mathbf{N i - Z n - F e - Z n - ~}$ $\mathbf{F e}-\mathbf{Z n}-\mathbf{N i}$ sequence displaying seven crystalline zones. Starting with the $\mathrm{Co}-\mathrm{Cu}-\mathrm{Co}$ welded crystal displaying the $\mathbf{C u}-\mathbf{C o}-\mathbf{C u}-\mathbf{C o}-$ $\mathrm{Cu}$ sequence (Figure $8 \mathrm{c}$ ), the same procedure using a solution containing $\mathrm{MnL}_{2}$ and $\mathbf{1}^{2+}$ afforded the core-shell crystal Mn@(Co-Cu-Co) displaying the Mn-Cu-Co-Cu-Co-Cu-Mn sequence (Figure 8d). Finally, starting with the $\mathbf{N i - C o - N i}$ welded crystal displaying the Co-Ni-Co-Ni-Co sequence (Figure $8 \mathrm{e})$, the same procedure using a solution containing $\mathrm{ZnL}_{2}$ and $\mathbf{1}^{2+}$ produced the core-shell crystal Zn@(Ni-Co-Ni) composed of seven crystalline zones with the $\mathbf{Z n}-\mathrm{Co}-\mathrm{Ni}-\mathrm{Co}-\mathrm{Ni}-\mathrm{Co}-\mathrm{Zn}$ sequence (Figure 8f).
Welded Crystals

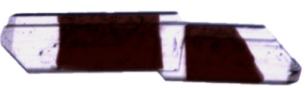

$\mathrm{Zn} F \mathrm{Zn}$ Fe $\mathrm{Zn}$

a

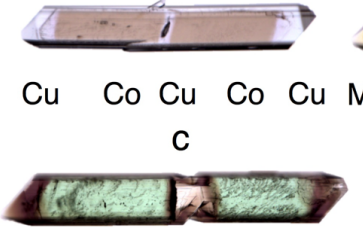

Co $\mathrm{Ni}$ Co $\mathrm{Ni}$ Co e

\section{Core-shell Crystals}

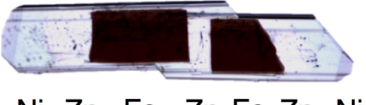

$\mathrm{Ni} \mathrm{Zn}$ Fe $\mathrm{Zn}$ Fe $\mathrm{Zn} \mathrm{Ni}$
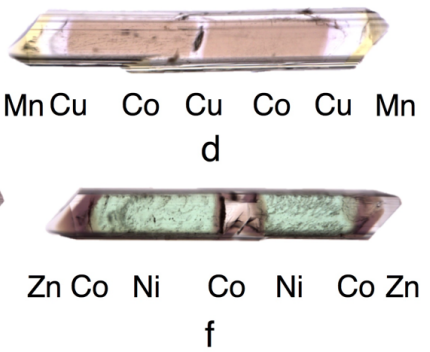

Figure 8: Photographs of two Fe based crystals welded by a $\mathrm{Zn}$ containing crystalline phase (a) and the core-shell crystal Ni@(Zn-Fe-Zn-Fe-Zn) with the Ni-Zn-Fe-Zn-Fe-Zn-Ni sequence and of two $\mathrm{Co}$ based crystals welded by a $\mathrm{Cu}$ containing phase (c) and the core-shell crystal Mn@(Cu-Co-Cu-Cu-Cu) with the $\mathbf{M n}-\mathbf{C u}-\mathbf{C o}-\mathbf{C u}-\mathbf{C o}-\mathbf{C u}-\mathbf{M n}$ sequence (d) and of two $\mathrm{Ni}$ based crystals welded by a Co containing crystalline phase (e) and the core-shell crystal Ni@(Zn-Fe-Zn-Fe-Zn) with the Ni-Zn-Fe-Zn-Fe-Zn-Ni sequence and of two Co based crystals welded by a $\mathrm{Cu}$ containing phase (c) and the core-shell crystal $\mathrm{Zn} @(\mathrm{Co}-\mathrm{Ni}-\mathrm{Co}-\mathrm{Ni}-\mathrm{Co})$ with the $\mathrm{Zn}-\mathrm{Co}-\mathrm{Ni}-\mathrm{Co}-\mathrm{Ni}-\mathrm{Co}-\mathrm{Zn}$ sequence (f).

In order to further extend the construction process, the formation of crystals composed of 9 zones was investigated. The strategy adopted may be based on the welding of two aligned and oriented core-shell crystals B@A (Figure 9a) by a crystalline phase $C$ leading to (B@A)-C-(B@A) welded crystals (Figure $9 \mathrm{~b})$. Again, by neglecting the growth process along the $a$ and $b$ axes, the welded crystal displays the $\boldsymbol{C}-\boldsymbol{B}-\boldsymbol{A}-\boldsymbol{B}-\boldsymbol{C}-\boldsymbol{B}-\boldsymbol{A}-\boldsymbol{B}$ $\boldsymbol{C}$ sequence along the $\mathrm{c}$ axis (Figure $9 \mathrm{c}$ ).

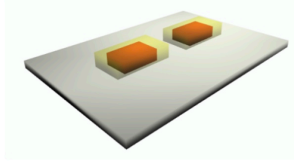

a

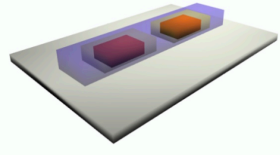

b

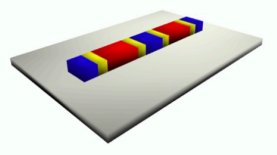

C

Figure 9: Schematic representations of two aligned core-shell crystals $B @(A(a)$ and the welded crystal $(B @ A)-C-(B @ A)$ by $C$ (b) leading to the $C-B-A-B-C-B-A-$ $B-C$ sequence (c) along the $C$ axis.

Experimentally, the above mentioned strategy was demonstrated by welding two aligned and oriented core-shell crystals (Cu@Co) (Figure 10a) by a solution containing $\mathrm{NiL}_{2}$ and 
$\mathbf{1}^{2+}$ cation leading to (Cu@Co)-Ni-(Cu@Co) single crystal (Figure 10b). The latter displays along the $\mathrm{c}$ axis the symmetric $\mathbf{N i}-\mathbf{C u}$ Co-Cu-Ni-Cu-Co-Cu-Ni sequence. Starting with two aligned and oriented core-shell crystals(Zn@Fe) (Figure 10c), the same procedure produced the welded crystal (Zn@Fe)-Ni-(Zn@Fe) displaying the $\mathbf{N i}-\mathbf{Z n}-\mathbf{F e}-\mathbf{Z n}-\mathbf{N i}-\mathbf{Z n}-\mathbf{F e}-\mathbf{Z n}-\mathbf{N i}$ symmetric sequence composed of nine different crystalline zones (Figure 10d). Finally, in order to verify the generality of the approach, two aligned and oriented core-shell crystals (Mn@Fe) (Figure 10e) were welded using a solution containing $\mathrm{ZnL}_{2}$ and $\mathbf{1}^{2+}$ cation leading to (Mn@Fe)-Zn-(Mn@Fe) single crystal (Figure 10b) displaying the $\mathbf{Z n}-\mathbf{M n}-\mathbf{F e}-\mathbf{M n}-\mathbf{Z n}-\mathbf{M n}-\mathbf{F e}-\mathbf{M n}-\mathbf{Z n}$ palindromic sequence along the $c$ axis.
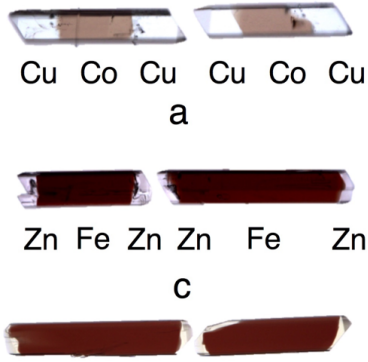

$\mathrm{Mn} F \mathrm{Fe} \mathrm{Mn}$ Fe $\mathrm{Mn}$ e

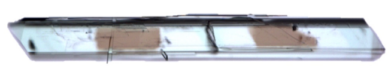

Ni Cu Co Cu NiCu Co CuNi $\mathrm{b}$

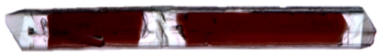

$\mathrm{NiZn} \mathrm{FeZn} \mathrm{NiZn} \mathrm{Fe} \mathrm{Zn} \mathrm{Ni}$

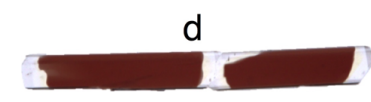

$\mathrm{ZnMn} \mathrm{Fe} \mathrm{Mn} \mathrm{ZnMn} \mathrm{Fe} \mathrm{MnZn}$ $\mathrm{f}$
Figure 10: Photographs of two core-shall crystals (Cu@Co) (a) welded by $\mathbf{1}_{2}-\mathrm{NiL}_{2}$ (b) two core-shall crystals (Zn@Fe) (c) welded by $\mathbf{1}_{2}-\mathrm{NiL}_{2}$ (d) and two core-shall crystals ( $\mathrm{Mn} @ \mathrm{Fe}$ ) (e) welded by $\mathbf{1}_{2}-\mathrm{ZnL}_{2}$ (f) leading to crystals displaying palindromic sequences composed of nine crystalline zones.

In conclusion, we have shown that, using a series of isostructural and almost isometric crystals differing by their colour, crystals with controlled sequence along the fastest growth axis can be designed and generated using a welding strategy in solution under mild conditions. The crystalline entity obtained displaying 5, 7 or 9 crystalline zones may be of interest for their optical properties owing to the differences in their refractive indices. The strategy presented here, although restricted to isostructural and almost isometric crystals, is rather versatile and may be applied to the design and preparation of a wide variety of crystalline materials. Research along these lines is currently under investigation using other series of crystals.

\section{Conflicts of interest}

There are no conflicts to declare.

\section{Acknowledgements}

We thank the University of Strasbourg, the C.N.R.S, the International centre for Frontier Research in Chemistry (icFRC), the Labex CSC (ANR-10-LABX- 0026 CSC) within the Investissement d'Avenir program ANR-10-IDEX-0002-02, the Ministère de l'Enseignement Supérieur et de la Recherche for financial support.

\section{Notes and references}

1 a) M. Simard, D. Su, J. D. Wuest, J. Am. Chem. Soc., 1991, 113, 4696-4698; b) S. Mann, Nature, 1993, 365, 499-505; c) M. W. Hosseini Acc. Chem. Res., 2005, 38, 313-323.

2 J.-M. Lehn, Supramolecular Chemistry, Concepts and Perspectives, VCH, Weinheim, 1995.

3 J. D. Dunitz, Pure Appl. Chem., 1991, 63, 177-185.

4 M. W. Hosseini, CrystEngCom., 2004, 6, 318-322.

5 (a) J. D. Wuest, Chem. Commun., 2005, 5830-5837; (b) M. W. Hosseini, Chem. Commun., 2005, 5825-5829.

6 a) G. M. Schmidt J. Pure Appl. Chem. 1971, 27, 647-678; b) G. R. Desiraju, Angew. Chem. Int. Ed. Engl., 1995, 34, 23112327; c) M. C. Etter, Acc. Chem. Res., 1990, 23, 120-126.

7 a) J. C. MacDonald, P. C. Dorrestein, M. M. Pilley, M. M. Foote, J. L. Lundburg, R. W. Henning, A. J. Schultz, J. L. Manson, J. Am. Chem. Soc., 2000, 122, 11692-11702; b) J. C. Noveron, M. S. Lah, R. E. Del Sesto, A. M. Arif, J. S. Miller, P. J. Stang, J. Am. Chem. Soc., 2002, 124, 6613-6625; c) T-J. M. Luo, J. C. MacDonald, G. T. R. Palmore, Chem. Mater., 2004, 16, 4916-4927; d) K. Sada, K. Inoue, T. Tanaka, A. Epergyes, A. Tanaka, N. Tohnai, A. Matsumoto, M. Miyata, Angew. Chem., Int. Ed., 2005, 44, 7059-7062; e) J. W. Steed, A. E. Goeta, J. Lipkowski, D. Swierczynski, V. Panteleon, S. Handa, Chem. Commun., 2007, 813-815 ; f) R. McNeil, P. Paukstelis, J. Adv. Mater., 2017, 29, 1701019 ; g) C. M. Balogh, L. Veyre, G. Pilet, C. Charles, L. Viriot, C. Andraud, C. Thieuleux, F. Riobé, O. Maury, Chem. Eur. J., 2017, 23, 1784-1788; h) M. Pan, Y-X. Zhu, K. Wu, L. Chen, Y-J. Hou, S-Y. Yin, H-P. Wang, YN. Fan, C-Y. Su, Angew. Chem. Int. Ed. 2017, 56, 14582-14586

8 a) S. Ferlay, M. W. Hosseini, Chem. Commun., 2004, 788-789; b) P. Dechambenoit, S. Ferlay, M. W. Hosseini, Cryst. Growth Des., 2005, 5, 2310-2312; c) P. Dechambenoit, S. Ferlay, N. Kyritsakas, M. W. Hosseini, Chem. Commun., 2009, 15591561; d) G. Marinescu, S. Ferlay, N. Kyritsakas, M. W. Hosseini, Chem. Commun., 2013, 11209-11211.

9 F. Zhang, C. R. R. Adolf, N. Zigon, S. Ferlay, N. Kyritsakas, M. W. Hosseini, Chem. Commun., 2017, 53, 3587-3590.

10 C. R. R. Adolf, S. Ferlay, N. Kyritsakas, M. W. Hosseini J. Am. Chem. Soc., 2015, 137, 15390-15393.

11 a) K. T. Holman, A. M. Pivovar, J. A. Swift, M. D. Ward Acc. Chem. Res., 2001, 34, 107-118; b) M. W. Hosseini, Coord. Chem. Rev., 2003, 240, 157-166.

12 S. Ferlay, M. W. Hosseini, In "Functional Supramolecular Architectures for organic electronics and nanotechnology", (Eds P. Samori and F. Cacialli) Wiley-VCH, Weinheim, 2001, 1, pp. 195. 


\section{Journal Name}

\section{COMMUNICATION}

\section{Graphical abstract}

Isostructural and almost isometric crystals differing by their colour may be welded in solution and under mild conditions into crystalline materials with imposed sequences.

Ni Cu Co Cu Ni Co Cu Ni 